\title{
Pengukuran Tingkat Kesiapan E-learning Guru di Kota Jayapura di Masa Pandemik Covid-19
}

\author{
Remuz MB Kmurawak ${ }^{1}$, Samuel Mandowen ${ }^{2}$, \\ ${ }^{1,2}$ Program Studi Sistem Informasi, Universitas Cenderawasih \\ ${ }^{1}$ Dewan Teknologi Informasi dan Komunikasi Provinsi Papua \\ E-mail: ${ }^{1}$ remuzbertho3@gmail.com, ${ }^{2}$ kanderaawin@gmail.com
}

\begin{abstract}
Abstrak
E-learning merupakan salah satu revolusi cara belajar yang mendorong percepatan pembelajaran yang berkualitas. Pandemik Covid-19 turut menjadi katalisator bagi percepatan implementasi $e$ learning di Kota Jayapura. Guru dituntut untuk dapat beradaptasi dalam menghadapi perubahan yang pesat. Meskipun e-learning merupakan keharusan diera pandemik, namun indikator kemajuan di Papua, menunjukan bahwa daerah ini mempunyai banyak kendala yang mesti dihadapi. Penelitian ini bertujuan untuk mengetahui sejauh mana tingkat kesiapan guru dalam menghadapi pembelajaran e-learning. Penelitian ini dilakukan dengan menyebarkan kuisioner kepada guru SD hingga SMA di wilayah Kota Jayapura, dengan faktor utama berupa infrastruktur teknologi, sumber daya manusia, dan konten. Hasil penelitian ini menunjukan bahwa berdasarkan persepsi guru, lebih dari 70 persen menggunakan google classroom sebagai platfom elearning, dengan tingkat kesiapan berapa pada level 3 (siap dengan sedikit perbaikan), indikator yang memerukan perhatian lebih adalah infrastruktur, akses internet serta penyediaan konten.
\end{abstract}

Kata kunci: kesiapan e-learning, guru, kota jayapura,

\begin{abstract}
E-learning is one of the revolutions in the education system that encourages the acceleration of quality learning. The Covid-19 pandemic has become a catalyst for accelerating the implementation of e-learning in Jayapura, Papua. Teachers are required to be able to adapt to this rapid change. Thus, E-learning becomes essential amid the pandemic, yet the ICT indicators reveal many barriers to implementing it. This study aims to assess the level of readiness of the teachers in implementing the e-learning system. Data was collected by distributing questionnaires to the teachers from elementary to high school in Jayapura City. Technology infrastructures, human resources, and e-learning content were the main variables to measure. This study indicated that based on teachers' perceptions, more than 70 percent were using google classroom as an e-learning platform. The level of readiness was level 3 (ready with minor improvements). Infrastructures, internet access, and e-learning content availability are the indicators that needed extra attention for improvement.
\end{abstract}

Keywords: e-learning readiness, teacher, Jayapura

\section{PENDAHULUAN}

Perkembangan teknologi memberikan pertumbuhan yang sangat pesat di sektor pendidikan . Hal tersebut pun telah merevolusi cara belajar [1]. Perubahan tersebut mendorong lembaga pendidikan untuk mencari platform terbaik untuk pendidikan yang berkualitas. [2]. Dalam kaitannya dengan pendidikan, guru merupakan aset utama dibidang akademik, dimana guru bertanggung jawab dalam menyampaikan ilmu pengetahuan kepada siswa. Pandemik COVID-19 serta penerapan kesehatan menuntut transisi yang sangat cepat kepada pembelajaran berbasis online (e-learning) [3]. Perubahan yang cepat ini memberikan kesempatan khusus untuk mengamati sejauh mana guru merasa siap untuk menerapkan e-learning [4]. Penting untuk diakui 
bahwa persepsi guru tentang kesiapan e-learning mempunyai permasalahan yang beragam.

Dalam rangka mengantisipasi pandemik Covid-19, pemerintah mengeluarkan peraturan daerah yang mengatur tentang pembelajaran pada masa pandemik. Peraturan tersebut menginstruksikan setiap sekolah di Indonesia untuk tutup pada kondisi tertentu. Kegiatan belajar mengajar yang awalnya dilakukan melalui interaksi tatap muka dialihkan ke sistem pembelajaran daring, dimana guru diharapkan dapat memberikan bahan ajar dengan menggunakan perangkat digital.[5], [6]. E-learning muncul sebagai pilihan untuk melaksanakan proses belajar mengajar di era pandemik. Dimana proses pembelajaran dilakukan dari rumah dengan menggunakan $e$ learning. [7]

E-learning memiliki banyak keunggulan. Febriani menjelaskan bahwa pembelajaran online memberikan dampak positif bagi siswa, yaitu meningkatkan kreativitas dan kemandirian siswa. Selain itu memungkinkan guru untuk melakukan inovasi penggunaan media sosial dan aplikasi pendukung pembelajaran. E-learning juga dapat diimplementasikan sebagai media alternatif dalam proses pembelajaran ketika kegiatan pembelajaran tidak dapat dilakukan melalui interaksi tatap muka.[8]. E-learning memberikan fleksibilitas waktu dan tempat serta meningkatkan efektivitas dalam mencari pengetahuan dan mengakses informasi. [9]

Implementasi dari $e$-learning membutuhkan kesiapan baik dari infrastruktur serta budaya dari institusi.[10]. Kesiapan ini dikenal sebagai E-learning Readiness (ELR). ELR dapat diartikan sebagai kesiapan mental atau fisik suatu organisasi untuk suatu pengalaman pembelajaran. Pengukuran implementasi ELR dibutuhkan untuk mengetahui kondisi serta kesesuaian strategi institusi dibandingkan dengan kondisi yang diharapkan [11].

Industri, pendidikan, pemerintah serta masyarakat merupakan komponen kunci dari $e$ learning readiness pada level pertama. Dalam level kedua, kesiapan e-learning dievaluasi berdasarkan hubungan, serta kapasitas suatu institusi untuk menyampaikan dan menggunakan tingkat literasi e-learning, serta training dan pelajaran termasuk konten dan budaya. [12].

Chapnick mengklaim beberapa faktor penilaian e-learning readiness. Faktor -faktor tersebut dikelompokan dalam 8 kategori yaitu psikologis, sosiologis, lingkungan, sumber daya manusia, kesiapan keuangan, technological skill, peralatan, serta content readiness. [13]. Aydin dan Tasci pun mengembangkan instrumen untuk mengukur tingkat ELR yang digunakan dinegara berkembang, yang terdiri atas faktor inovasi, teknologi, manusia, serta pengembangan diri. Keempat faktor tersebut dipengaruhi oleh tiga variabel lainnya yaitu: resources, skills dan attitudes [14]. Dalam penelitian yang dilakukan oleh Lopez dan evaluasinya terhadap ELR, diperoleh model ELR di institusi pendidikan yang terdiri dari enam dimensi, yaitu: business, technology, content, culture, human resource, serta financial. [15].

Kaur dan Abas pun mengkategorikan faktor pengukur kesiapan e-learning ]dalam 8 kategori, ketika melakukan penelitian ELR di Open University Malaysia. [16]. Adapun kategori tersebut adalah: learner, management, personnel, content, technical, environmental, cultural dan financial readiness. Dalam penelitian yang dilakukan oleh Saekow dan Samson pada perguruan tinggi di Thailand menggunakan 5 kategori penentu kesiapan implementasi $e$-learning, yaitu policy, technology, financial, human resources, dan infrastructures. [12]. Sedangkan Mailany menyimpulkan 5 faktor kunci yang mengukur kesiapan e-learning pada perguruan tinggi di Indonesia, yaitu: policies (kebijakan), technology infrastructure, human resources, financial dan content.[17].

Meskipun banyak penelitian yang telah mengidentifikasi berbagai keuntungan penerapan $e$ learning namun pada kenyataannya tidak semua institusi yang menggunakan e-learning mendapatkan hasil yang sesuai harapan.[18]. Kondisi Provinsi Papua dengan tingkat penetrasi internet paling rendah 3\%, tentu membutuhkan perhatian yang lebih serius. [19].Kendala yang lain juga disebabkan oleh Indeks Pembangunan - Teknologi Informasi dan Komunikasi (IP-TIK) Provinsi Papua yang menempati posisi terendah di indonesia pada tahun 2018 hingga 2019 [20]. Dimana IP-TIK ini ditentukan oleh 3 kategori yaitu infrastruktur, penggunaan dan keahlian. Berdasarkan fakta yang ada, implementasi e-learning membutuhkan kerja keras dari semua stakeholder untuk dapat memberikan hasil yang terbaik, bagi pendidikan ditanah Papua.

Penelitian ini bertujuan untuk bertujuan untuk menganalisis kesiapan guru dalam 
menerapkan e-learning pada masa Covid-19. Penelitian ini dilakukan di Kota Jayapura, dikarenakan secara infrastruktur, kota ini jauh lebih siap dibandingkan kota atau kabupaten lain di wilayah Papua.

\section{METODE PENELITIAN}

Dalam penelitian ini, model yang digunakan diadopsi dari Lopez, Saekow dan Meliani, dimana berfokus pada persepsi guru. Berikut adalah tahapan penelitian yang digunakan dalam penelitian ini disajikan dalam bentuk diagramsebagai berikut:

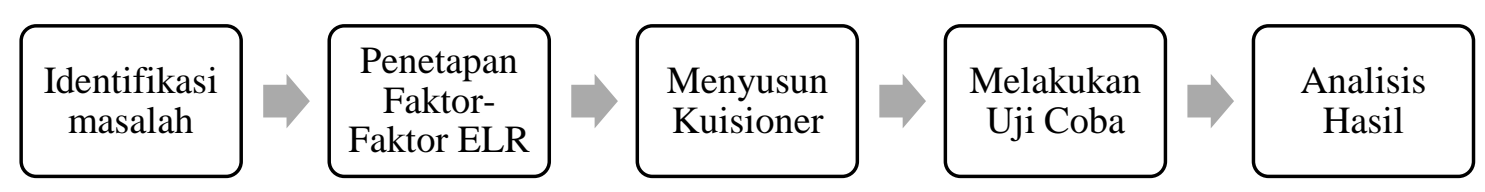

Gambar 1 Tahapan Penelitian ELR

Metode pengumpulan data yang digunakan dalam survey ini berasal dari guru sekolah yang dapat mengetahui kesiapan penerapan e-learning. Proses pengumpulan dilakukan secara online menggunakan google form. Penyebaran kuisioner bekerja sama dengan Dinas Pendidikan Kota Jayapura, untuk diteruskan kepada sekolah-sekolah di lingkungan Kota Jayapura. Data yang digunakan dalam penelitian ini merupakan data primer berdasarkan kuisioner yang dibagikan kepada responden, yaitu guru aktif di daerah Kota Jayapura.

Tabel 1 Daftar Faktor dan Penelitian Pendukungnya

\begin{tabular}{|l|c|c|c|c|c|}
\hline \multicolumn{1}{|c|}{ Kategori } & Chapnick & Lopez & $\begin{array}{c}\text { Aydin dan } \\
\text { Tasci }\end{array}$ & $\begin{array}{c}\text { Kaur \& } \\
\text { Abas }\end{array}$ & $\begin{array}{c}\text { Saekow dan } \\
\text { Samson }\end{array}$ \\
\hline $\begin{array}{l}\text { Technology } \\
\text { Infrastructures }\end{array}$ & $\mathrm{v}$ & $\mathrm{v}$ & $\mathrm{v}$ & & $\mathrm{v}$ \\
\hline Human resources & $\mathrm{v}$ & $\mathrm{v}$ & $\mathrm{v}$ & $\mathrm{v}$ & $\mathrm{v}$ \\
\hline Content & & $\mathrm{v}$ & & $\mathrm{v}$ & $\mathrm{v}$ \\
\hline
\end{tabular}

Hasil penelitian ini menghasilkan skor yang dapat menentukan peringkat kesiapan elearning institusi. Model ELR dapat membantu manajemen untuk mengukur tingkat kesiapan institusi dalam mengimplemantasikan e-learning, mengetahui faktor terkuat serta faktor yang perlu perhatian untuk pendampingan dalam kesinambungan pengembangan e-learning.

Kuisioner dibuat berdasarkan e-learning readiness yang terdiri dari 5 faktor ELR. Setiap faktor dijabarkan dalam indikator kunci,yang akan dibuat dalam setiap detail pertanyaan. Skala lickert menggunakan 5 skala pengukuran yaitu 1 = "Sangat Tidak Setuju", 2 = "Tidak Setuju", 3="Netral", 4="Setuju" dan 5="Sangat Setuju". Kuesioner didistribusikan kepada responden berdasarkan indikator yang mengacu ke faktor pengukuran e-learning readiness. 
Tabel 2 Daftar indikator untuk setiap faktor e-learning readiness

\begin{tabular}{|l|l|l|}
\hline \multicolumn{1}{|c|}{ Faktor } & \multicolumn{1}{|c|}{ Indikator } & \multicolumn{1}{c|}{ Penelitian Pendukung } \\
\hline Technology Infrastructure & Akses Internet & {$[21][22]$} \\
\hline \multirow{2}{*}{ Human Resources } & Motivasi & \multirow{2}{*}[21]{} \\
\cline { 2 - 2 } & Kompetensi Teknis & \multirow{2}{*}{ [23] } \\
\hline \multirow{2}{*}{ Content } & Ketersediaan Konten & Ketersediaan Pembuat Konten \\
\cline { 2 - 2 } &
\end{tabular}

Selanjutnya digunakan lima tingkat likert-scale yang merupakan dasar untuk menilai tingkat persetujuan dari subjek penelitian. Skala pengukuran tingkat kesiapan e-learning merupakan suatu alat ukur yang dapat memberi gambaran status kesiapan suatu organisasi terhadap implementasi sistem pembelajaran tersebut.

Adapun metode perhitungan skor didasarkan pada skor kesiapan perindikator dimana:

$\begin{array}{ll}\text { Skor pertanyaan } & =\frac{\sum \text { nilai pertanyaan }}{\text { jumlah responden }} \\ \text { Skor indikator } & =\frac{\sum \text { skorpertanyaan }}{\text { jumlah pertanyaan }} \\ \text { Skor perfaktor } & =\frac{\sum \text { skorindikator }}{\text { jumlah indikator }} \\ \text { Skor total } & =\frac{\sum \text { skorperfaktor }}{\text { jumlahtotalfaktor }}\end{array}$

Untuk mengetahui atau memetakan tingkat kesiapan organisasi digunakan skala Aydin dan Tasci yang membagi kesiapan dalam empat level sebagai berikut:

Tabel 3 Status Level kesiapan ELR Aydin dan Tasci Skor

\begin{tabular}{|l|l|l|}
\hline \multicolumn{1}{|c|}{ Skor } & \multicolumn{1}{|c|}{ Status } & \multicolumn{1}{|c|}{ Level } \\
\hline $1.00-2.60$ & Not ready need a lot of work & Level 1 \\
\hline $2.61-3.40$ & Not ready need some work & Level 2 \\
\hline $3.41-4.20$ & Ready, but needs a few improvement & Level 3 \\
\hline $4.21-5.00$ & Ready go ahead & Level 4 \\
\hline
\end{tabular}

\section{HASIL DAN PEMBAHASAN}

Hasil kuisioner diikuti oleh 270 responden yang tersebar pada sekolah di Kota Jayapura, pada jenjang SD, SMP hingga SMA. Hasil pengisian kuisioner dari Google Form, ditampilkan sebagai berikut:

Tabel 4 Profil Responden

\begin{tabular}{|l|l|c|c|}
\hline \multicolumn{1}{|c|}{ Variabel } & \multicolumn{1}{|c|}{ Kategori } & Frekuensi & Persentase \\
\hline Usia & 20-29 tahun & 47 & 17,7 \\
\hline & 30-39 tahun & 89 & 33,5 \\
\hline & 40-49 tahun & 64 & 24,1 \\
\hline & 50-59 tahun & 66 & 24,8 \\
\hline & Total & 266 & 100,0 \\
\hline Jenjang Sekolah & SD & 248 & 91,9 \\
\hline & SMP & 13 & 4,8 \\
\hline & SMA & 9 & 3,3 \\
\hline & Total & 270 & 100,0 \\
\hline Status Sekolah & Negeri & 197 & 73,0 \\
\hline & Swasta & 73 & 27,0 \\
\hline & Total & 270 & 100,0 \\
\hline
\end{tabular}


Berdasarkan Tabel 4, profil dari responden mengungkapkan mayoritas memiliki usia 30an dan diikuti oleh 50-an dengan 30,3\% dan 24,8\%. Di samping itu, mayoritas guru yang mengisi kuisioner berasal dari jenjang sekolah dasar (91.9\%) dengan status sekolah negeri (73\%).

Google Classroom merupakan platform e-learning yang paling banyak digunakan disekolah, dengan persentasi lebih dari 70\%. Sedangkan LMS lainnya 6\% dan Moodle 5\%. Hal yang menarik adalah terdapat $14 \%$ responden yang melakukan pembelajaran secara online. Guru akan memberikan tugas secara manual melalui kertas yang telah difotocopy, kemudian siswa akan mengerjakannya dirumah, kemudian dikumpulkan pada selang waktu tertentu. Langkah ini terpaksa diambil dikarenakan fasilitas yang tidak memadai, khususnya di siswa, dimana terdapat siswa yang tidak mempunyai perangkat yang memadai (baik handphone maupun notebook). Proses komunikasi yang terjadi antara guru menggunakan aplikasi Whatsapp dan SMS. Jika siswa mempunyai pulsa yang memadai, maka proses belajar mengajar dapat melalui aplikasi video converences seperti Zoom, Google Meet maupun Microsoft Team. Tentu hal tersebut harus didukung oleh media pembelajaran yang menunjang seperti handphone, laptop atau tablet.

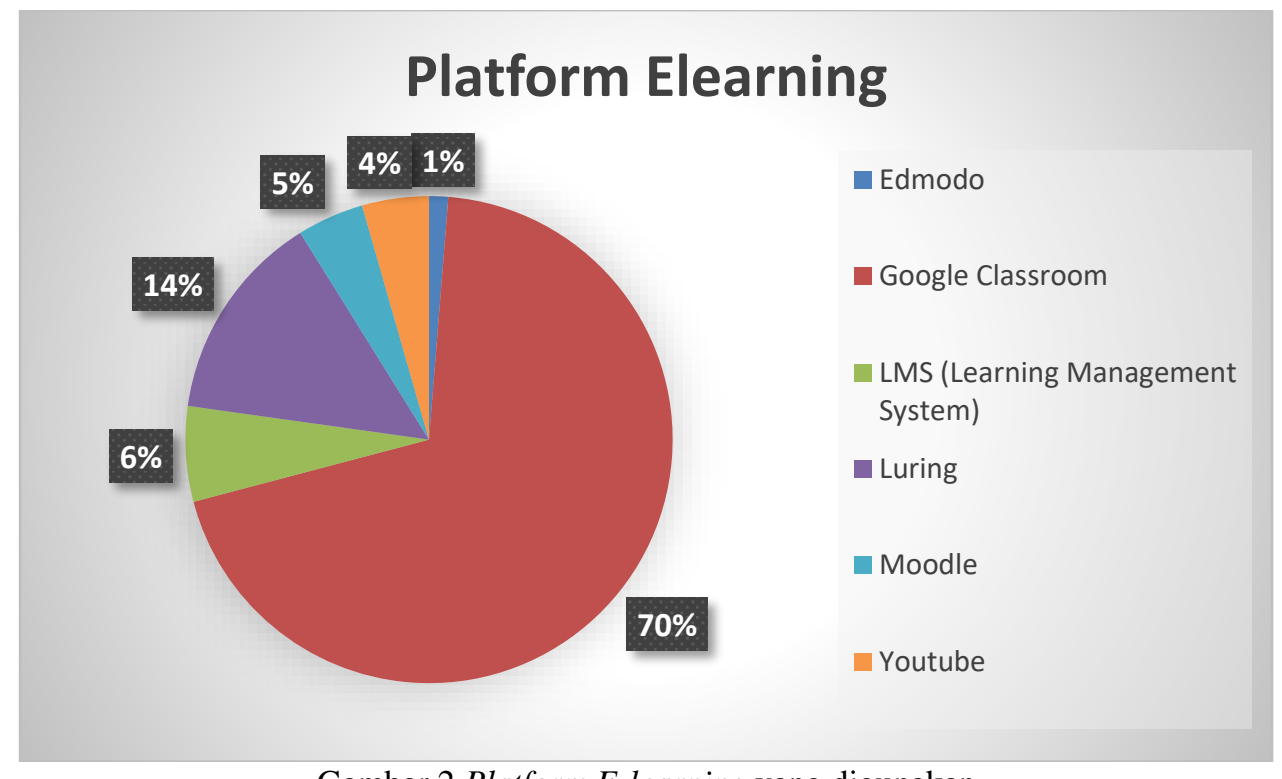

Gambar 2 Platform E-learning yang digunakan

Persepsi guru, tentang kesiapan e-learning mencakup indikator akses internet, motivasi, kompetensi teknis, ketersediaan konten serta ketersediaan pembuat konten, dijabarkan dalam tabel berikut:

Tabel 5 E-learning Readines berdasarkan Persepsi Guru

\begin{tabular}{|c|c|c|c|c|c|}
\hline Deskripsi & $\begin{array}{c}1(\%) \\
\text { Sangat } \\
\text { tidak } \\
\text { setuju }\end{array}$ & $\begin{array}{c}2(\%) \\
\text { Tidak } \\
\text { setuju }\end{array}$ & $\begin{array}{l}3(\%) \\
\text { Netral }\end{array}$ & $\begin{array}{l}4(\%) \\
\text { Setuju }\end{array}$ & $\begin{array}{c}5(\%) \\
\text { Sangat } \\
\text { Setuju }\end{array}$ \\
\hline $\begin{array}{l}\text { Jumlah komputer di sekolah sudah mencukupi untuk digunakan dalam } \\
\text { sistem pembelajaran } e \text {-learning }\end{array}$ & 10,4 & 15,9 & 17,8 & 24,1 & 31,9 \\
\hline $\begin{array}{l}\text { Sekolah memiliki komputer yang terhubung ke internet dengan koneksi } \\
\text { yang stabil }\end{array}$ & 8,9 & 12,2 & 19,3 & 26,7 & 33,0 \\
\hline Kecepatan akses internet di sekolah sudah memuaskan & 4,1 & 12,2 & 24,1 & 35,2 & 24,4 \\
\hline Sekolah memiliki area hotspot merata dengan koneksi yang stabil. & 7,4 & 16,3 & 28,5 & 28,5 & 19,3 \\
\hline $\begin{array}{l}\text { Saya memiliki motivasi yang tinggi untuk mengajar secara online karena } \\
\text { dapat memudahkan saya }\end{array}$ & 4,1 & 8,9 & 23,0 & 29,3 & 34,8 \\
\hline Saya memiliki komitmen yang tinggi untuk mengajar. & 0,0 & 0,7 & 5,6 & 29,6 & 64,1 \\
\hline $\begin{array}{l}\text { Saya mengerti cara menyimpan atau membuka file dokumen dari harddisk } \\
\text { atau flashdisk. }\end{array}$ & 1,1 & 3,3 & 11,5 & 23,0 & 61,1 \\
\hline
\end{tabular}




\begin{tabular}{|l|c|c|c|c|c|}
\cline { 4 - 5 } Saya mengerti cara navigasi halaman web & 1,9 & 9,6 & 20,0 & 34,1 & 34,4 \\
\hline $\begin{array}{l}\text { Saya mengerti cara mengunduh/mendownload File menggunakan browser } \\
\text { (firefox, internet explorer, chrome). }\end{array}$ & 1,1 & 4,4 & 14,1 & 29,6 & 50,7 \\
\hline $\begin{array}{l}\text { Saya dapat mengekspresikan diri saya dalam tulisan (seperti: perasaan, } \\
\text { humor, emosi). }\end{array}$ & 1,1 & 3,7 & 16,7 & 42,6 & 35,9 \\
\hline $\begin{array}{l}\text { Saya mampu untuk menggunakan online tools (email, chat) untuk } \\
\text { mengerjakan tugas dengan siswa lain di tempat yang berbeda. }\end{array}$ & 4,8 & 9,3 & 19,6 & 31,1 & 35,2 \\
\hline $\begin{array}{l}\text { Konten materi yang berbentuk elektronik (text, gambar, animasi, video) } \\
\text { sudah tersedia lengkap dan siap untuk digunakan. }\end{array}$ & 4,1 & 10,4 & 25,2 & 33,3 & 27,0 \\
\hline $\begin{array}{l}\text { Sarana untuk pembuatan konten materi elektronik (kamera, editor gambar, } \\
\text { flash, PDF editor) dalam berbagai format sudah tersedia dengan lengkap. }\end{array}$ & 5,6 & 14,1 & 25,2 & 31,5 & 23,7 \\
\hline
\end{tabular}

Berdasarkan item kuisioner pada Tabel 5, dapat dilihat bahwa, faktor tertinggi yang disetujui oleh guru adalah berkaitan dengan komitmen mengajar yang tinggi, serta kemampuan untuk membuka file pada media penyimpanan, yaitu $64,1 \%$ dan $61,1 \%$. Faktor ketiga mengenai keahliah teknis guru dalam mengunduh file dengan browser yang ada dengan persentasi sebesar $50,7 \% /$ disisi lain, terdapat beberapa item quisioner yang juga tidak bersesuaian dengan pendapat guru, yaitu berkaitan dengan infrastruktur TIK di sekolah. 10,4\% guru tidak setuju bahwa jumlah komputer disekolah sudah mencukupi bagi proses pembelajaran online2 faktor lainnya adalah guru tidak sependapat mengenai koneksi internet yang stabil serta (8.4\%) dan area hotspot yang merata $(7.4 \%)$. Sedangkan beberapa faktor lainnya adalah turut mempengaruhi dalam pembobotan pada setiap indikator penilaian. Jika data tersebut diakumulasi, maka akan memperoleh hasil sebagai berikut :

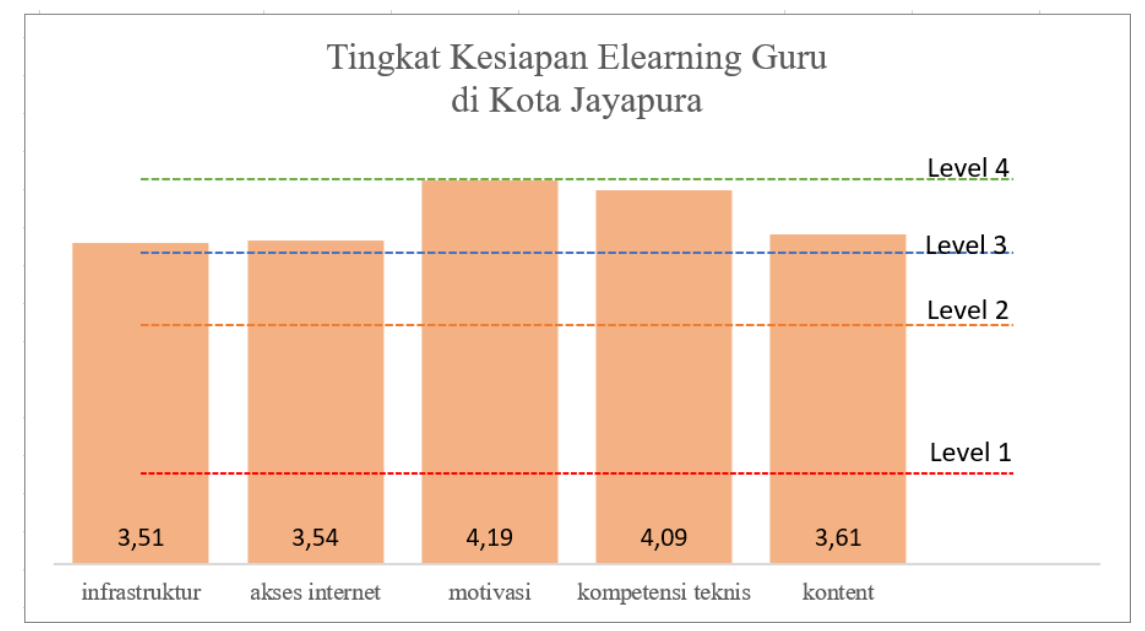

Gambar 3 Bobot indikator E-learning Readiness Guru di Kota Jayapura.

Secara keseluruhan, 5 indikator yang diteliti berada pada level 3, yaitu "siap, dengan sedikit peningkatan". Indikator tertinggi dari tingkat kesiapan e-learning guru di Kota Jayapura berhubungan dengan faktor human resources, yaitu indikator motivasi (4.19) dan kompetensi teknis $(4,09)$, sedangkan 3 faktor terendah dalah kesiapan e-learning adalah konten $(3,61)$, akses internet $(3,54)$ serta kesediaan infrastruktur $(3,51)$. Ketiga hal ini memerlukan perhatian serius dalam rangka meningkatkan kesiapan e-learning bagi guru di Kota Jayapura. Hal ini sejalan dengan saran masukan dari guru yang menginginkan koneksi internet yang cepat dan stabil di wilayah sekolah, serta sarana pendukung yang lebih baik. Beberapa guru juga menyarankan diselenggarakan pelatihan bagi peningkatan kapasitas guru, khususnya dalam membuat konten pembelajaran yang menarik yang akan menolong guru memberikan materi 


\section{KESIMPULAN DAN SARAN}

Secara umum tingkat kesiapan E-learning bagi guru dilingkungan Kota Jayapura berada pada nilai 3,76 yang artinya berada pada level 3 (Ready, but needs a few improvement). Nilai paling rendah yang memerlukan perhatian serius oleh pembuat kebijakan, berhubungan dengan infrastruktur TIK, serta akes internet. Faktor lain yang tidak kalah penting berhubungan dengan konten. Data yang ditunjukan dari indeks e-learning readiness ini menunjukan organisasi masih memerlukan langkah-langkah perbaikan atau peningkatan agar dapat mendukung keberhasilan penerapan e-learning.

Saran penelitian selanjutnya adalah analisis statistik untuk mengkaji faktor-faktor ELR apa saja yang berpengaruh secara signifikan terhadap keberhasilan implementasi e-learning di sekolah dari yang mencakup seluruh stakeholder, yaitu siswa, pimpinan, maupun tenaga IT

\section{UCAPAN TERIMA KASIH}

Ucapan terima kasih kepada Dewan Teknologi Informasi dan Komunikasi (WANTIKDA) Provinsi Papua yang turut mendukung pelaksanaan Penelitian ini.

\section{DAFTAR PUSTAKA}

[1] K. Basak, S. Wotto, M. Bélanger, and Paul, "E-learning, M-learning and D-learning: Conceptual definition and comparative analysis," E-learning Digit. Media, vol. 15, no. 4, pp. 191-216, 2018, doi: 10.1177/2042753018785180.

[2] R. J. Ventayen, "Teachers' Readiness in Online Teaching Environment: A Case of Department of Education Teachers," J. Educ. Manag. Soc. Sci., vol. 2, no. 1, 2018, [Online]. Available: www.psurj.org/jemss.

[3] R. Scherer, S. K. Howard, J. Tondeur, and F. Siddiq, "Profiling teachers' readiness for online teaching and learning in higher education: Who's ready?," Comput. Human Behav., vol. 118, no. January 2021, p. 106675, 2021, doi: 10.1016/j.chb.2020.106675.

[4] D. C. Brooks and S. Grajek, "Faculty Readiness to Begin Fully Remote Teaching," 2020. https://er.educause.edu/blogs/2020/3/faculty-readiness-to-begin-fully-remote-teaching (accessed Aug. 20, 2021).

[5] Kementerian Pendidikan dan Kebudayaan, Kepmendikbud Nomor 719/P/2020 tentang Pedoman Pelaksanaan Kurikulum pada Satuan Pendidikan dalam Kondisi Khusus. 2020, p. 9.

[6] Kementerian Pendidikan dan Kebudayaan, "Penyesuaian Kebijakan Pembelajaran di Masa Pandemi COVID-19," 2020. [Online]. Available: https://www.kemdikbud.go.id/main/blog/2020/08/kemendikbud-terbitkan-kurikulumdarurat-pada-satuan-pendidikan-dalam-kondisi-khusus.

[7] T. Andarwulan, T. A. Al Fajri, and G. Damayanti, "Elementary teachers' readiness toward the online learning policy in the new normal era during Covid-19," Int. J. Instr., vol. 14, no. 3, pp. 771-786, 2021, doi: 10.29333/iji.2021.14345a.

[8] S. R. Febriani, R. Widayanti, M. A. Amrulloh, and N. Mufidah, "Arabic Learning for Elementary School during COVID-19 Emergency in Indonesia," OKARA J. Bhs. dan Sastra, vol. 14, no. 1, p. 67, 2020, doi: 10.19105/ojbs.v14i1.3194.

[9] V. Arkorful and N. Abaidoo, "The role of e-learning, advantages and disadvantages of its adoption in higher education," Int. J. Instr. Technol. Distance Learn., vol. 12, no. 1, pp. 29-42, 2015.

[10] D. Napitupulu, K. Adiyarta, D. Abdullah, and D. Murtiningsih, "Proposed ELR Model for E-learning Readiness Evaluation Based on McKensey 7S Framework," no. 6, 2019, doi: 10.4108/eai.18-7-2019.2288544.

[11] K. Adiyarta, D. Napitupulu, R. Rahim, D. Abdullah, and M. I. Setiawan, "Analysis of $e$ learning implementation readiness based on integrated elr model," J. Phys. Conf. Ser., 
vol. 1007, no. 1, 2018, doi: 10.1088/1742-6596/1007/1/012041.

[12] A. Saekow and D. Samson, "E-learning Readiness of Thailand's Universities Comparing to the USA's Cases," Int. J. e-Education, e-Business, e-Management e-learning, vol. 1, no. 2, 2011, doi: 10.7763/ijeeee.2011.v1.20.

[13] Samantha Chapnick, "Are You Ready for E-learning?," 2000. https://nurhadiw.files.wordpress.com/2010/08/are_you_ready_for_e-learning.pdf.

[14] C. H. Aydin and D. Tasci, "Measuring readiness for e-learning: Reflections from an emerging country," Educ. Technol. Soc., vol. 8, no. 4, pp. 244-257, 2005.

[15] C. T. Lopes, "Evaluating e-learning readiness in a health sciences higher education institution," Proc. IADIS Int. Conf. e-learning, EL 2007 - Part IADIS Multi Conf. Comput. Sci. Inf. Syst. MCCSIS 2007, vol. 1, no. July, pp. 59-67, 2007.

[16] K. Kaur and Z. W. Abas, "An assessment of e-learning readiness at Open University Malaysia.," in International Conference on Computers in Education., 2004, vol. 88, no. 2, pp. 231-233, doi: 10.1016/0014-5793(78)80181-1.

[17] M. Mailany, "Analisis Faktor-Faktor Pengukuran Tingkat Kesiapan Implementasi Elearning di Perguruan Tinggi," 2015.

[18] D. Napitupulu, "Kesiapan Implementasi Sistem e-learning di Lingkungan Universitas XYZ," in Seminar Nasional Technopreneurship dan Alih Teknologi, 2016, no. October 2016.

[19] APJII, "Penetrasi \& Perilaku Pengguna Internet Indonesia Survey 2017," Teknopreneur, vol. 2018, no. 31 August 2018, p. Hasil Survey, 2017.

[20] Badan Pusat Statistik, Indeks Pembangunan Teknologi Informasi dan Komunikasi. 2019.

[21] C. A. Mercado, "Readiness Assessment Tool for An e-learning Environment Implementation," Fifth Int. Conf. e-learning Knowledge-Based Soc., no. 2005, pp. 1-11, 2008.

[22] S. K. Sharma, S. Gulsecen, Z. Ozen, and E. Kartal, "Assessing E-learning Readiness of Instructors in Turkey Sushil," vol. 1, no. 3, p. 24, 2015, [Online]. Available: https://www.researchgate.net/publication/262808265_Assessing_E-

learning_Readiness_of_Instructors_in_Turkey.

[23] W. Sulistio, "Pengukuran Kesiapan Implementasi E-learning: Studi Kasus Pusdiklat XYZ," Universitas Indonesia, 2013. 